\title{
Research on the Optimal Design of Soccer Robot based on the Mechanical Analysis
}

\author{
Chunxi Zhao \\ Jilin Agricultural University, Changchun 130118, China \\ aemail: 10821395@qq.com
}

\begin{abstract}
Keywords: Optimal Design Open Experiment; Network Platform; Wireless Network
\end{abstract}
\begin{abstract}
Aimed at the problems existed in current opening laboratory system are analyzed, and puts forward the improvement of the platform, design with learning resources, map navigation guide, wireless service platform and other functions, to achieve a unified platform, sharing interface, the introduction of wireless network technology network open system platform for experiments related to the teaching of teachers and students and provide more convenient.
\end{abstract}

\section{Introduction}

Open experimental teaching has become an important part of University teaching. Many colleges and universities to open experimental teaching to establish the corresponding experimental booking system and management system of network platform, with the help of information network environment to support the convenience of opening experimental teaching. However, with the deepening of the open experiment teaching and practice teaching reform and the network technology, especially wireless network technology development, the first generation of experiment teaching network platform has become functional single, more can meet the experimental teaching, learning and management needs [1]. Based on the comprehensive utilization of wired networks and wireless networks, this paper establishes a comprehensive resource based network platform with diverse functions and advanced technologies [2-3].

\section{The Main Characteristics of Comprehensive Resource Support Platform}

Resource rich, functional diversity, reflecting the student centered teaching thought early open experiment management system basically only provides a single experiment appointment, management function. However, after the appointment of students, more important is still need to preview before the experiment class, review, check the relevant information, and even before the appointment will need to find a variety of learning resources. We build a comprehensive resource support platform and the learning resource library will be able to meet the needs of the students. Also due to the distribution of various school laboratories, quite a part of students is not easy to find the lab, and the specific location, developed a network map guide system, help students more convenient to find the place, which takes the students as the center of thought [4].

Unified platform, sharing the next day, the introduction of wireless network technology. Due to historical reasons, the various departments of the school have established independent information management systems, such as the educational system, school system, logistics system, etc.. But at the beginning of the establishment, these management systems did not design a common ground, which led to repeated authentication of the same user. And the platform is developed a shared interface, the same user login to the open laboratory network platform in need again authentication can enter into the educational system the user has been registered in the system and, which in a large extent save trouble caused by repetition of the user input, and ensure safety of the system. In addition, the use of modern wireless network technology to build up the SMS platform will be given to the experimental teaching of teachers and students to provide more convenient. 


\section{The main functions of the integrated resource based support platform}

Open network platform of comprehensive experimental dielectric resources reflect the new situation and new requirements of new technology and new content. In the new situation of the reform of the practice teaching, the new network technology is used to present the relevant parties to the open experiment [5]. It is a comprehensive resource based network platform, which is a set of experiment reservation, experiment management, learning resource database, network map guide system and wireless network service (SMS platform). Main contents are:

\section{Experiment reservation and management system}

This module mainly includes three aspects: the student appointment subsystem, the teacher management subsystem, the experiment management personnel subsystem. Its system structure is shown in figure 1.

Learning Resource Repository

The learning resource base is mainly provide graduate students about the experiment, rich and diversified learning materials, a collection of covers all school department laboratory data. All these data according to the text, images, audio, and video for processing and classification. Each resource library and contains the subject under all experimental course teaching documents, teacher introduction, experimental guide books, experimental schematic diagram, preview, review questions, audio, video and other. It is presented in the form of multimedia, and provides users with query, download and application services. Resource library based on two categories: first, according to the media material classification, divided into courseware library, learning document library, graphics and image library, audio library, video library, animation library, etc. two are classified according to the school discipline. Mountain in the characteristics of these materials is a large amount of data, data types and large difference, the organization and storage of the database by the impact of the connection. For the convenience of management, the establishment of the same table in the library, used to store small the same kind of material. The material number is the only material identification mark. Subject classification specified its subject material, it is classified as one of the attributes, search keywords; also as a means to provide the retrieval, storage path refers to the material access position.

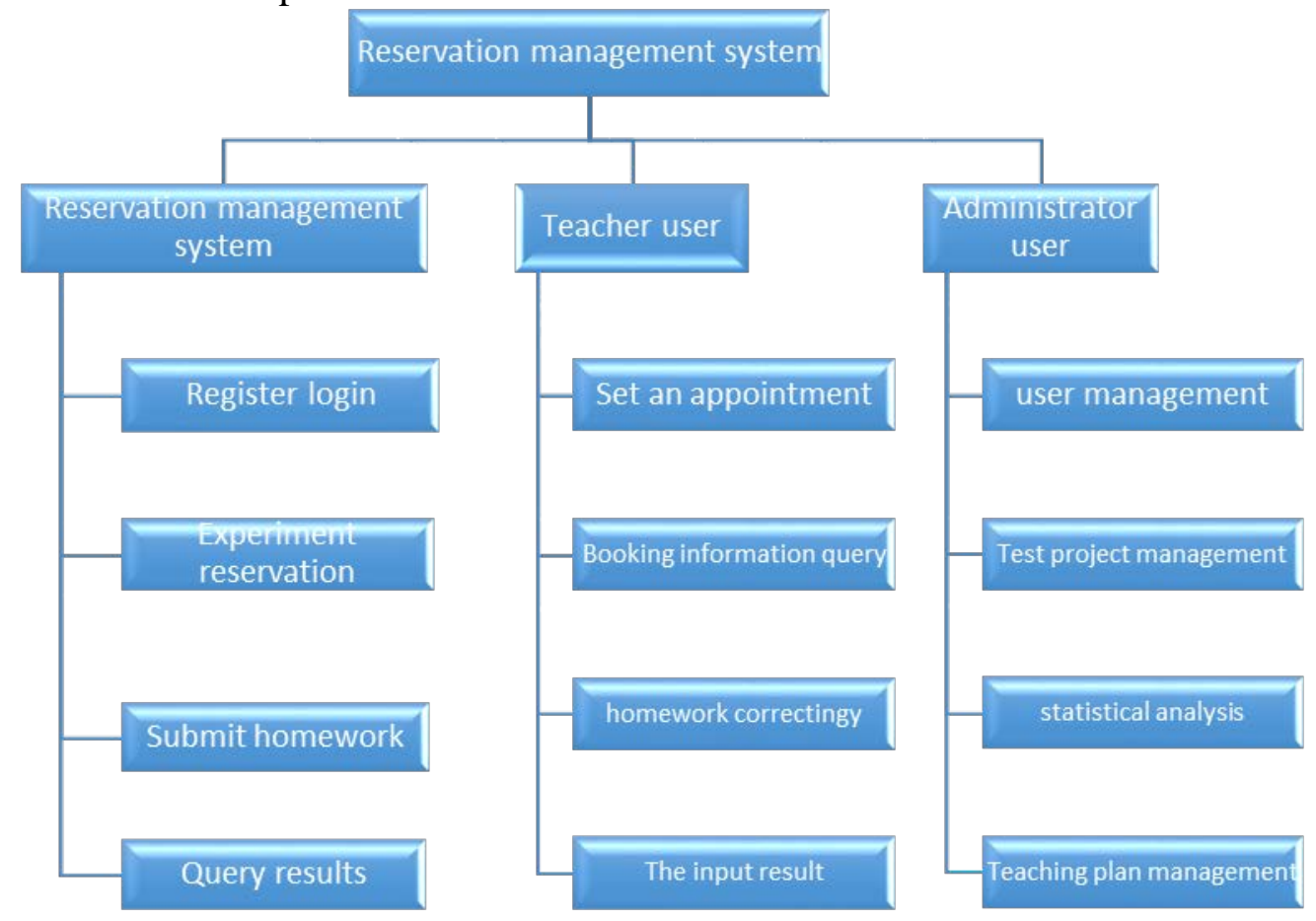

Figure1. Structure diagram of experimental system 
The structure of the resource pool is divided into three levels, namely the user layer, application layer, database service layer, as shown in figure 2. The user layer, the user need only through the browser visit can; application layer user is actually a database administrator, he through the log on the web server can realization of resource database query, classification, add, modify, such as work, namely resource database has any change is through him to operate the; the lowest layer is the database service layer, uses the disk array technology, can always increase the hard, do not have to worry about lack of hard disk capacity.

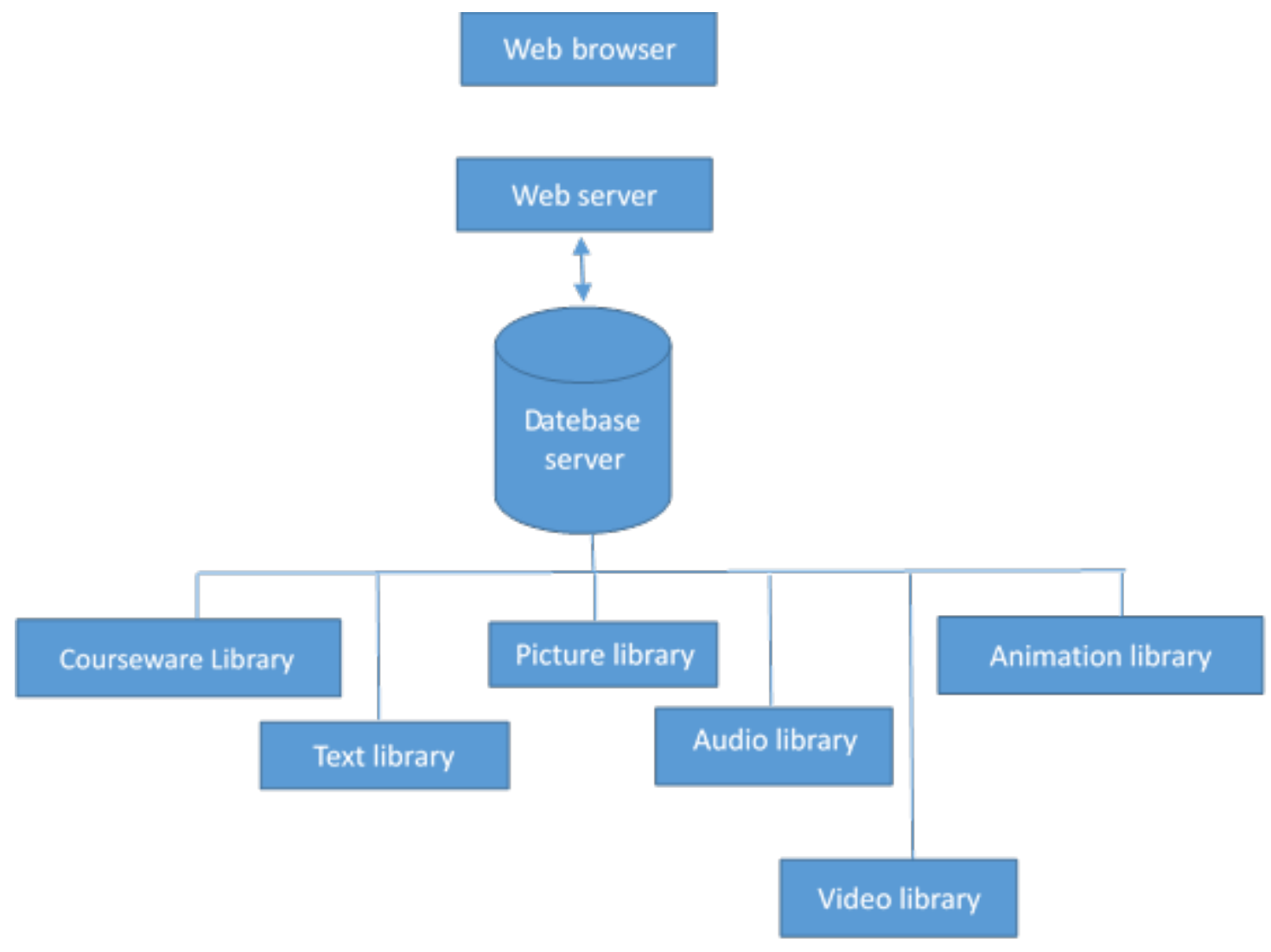

Figure2. Structure of teaching resources library

Network map guide system

At present, the campus area is relatively large, each research laboratory building, etc. in every corner of the campus distribution. According to the feedback from students, a considerable part of the students to do experiments to find a small place, even to find a place in which one does not know the classroom, this needs to ask people, very convenient. In order to solve this problem, we have set up an online map guide system, which is a new and high technology to store and process the information of computer graphics and database. The geography and related attributes together organically, according to actual needs accurate true, illustrations displayed to the user. Online map guide system based on the GIS technology as the foundation, integration of the database technology, the electronic map and the geographic location of the data visualization, rich in content, it's convenient to search information, intelligent degree higher characteristic. Through such a virtual map to guide students to reach their own places to go, of course, the system can be further extended to all the staff to use.

The wireless network (SMS) service platform

With the extension of GSM and CDMA network coverage, the application Short Message technology of these two kinds of network is more and more widely based on. This technology can break the space constraints, can be widely used in the layout of the wired communication network not convenient place, can make up to a certain extent, the small foot cable network. Experimental teaching in its own involves widely, a long time span, the experiment site dispersion characteristics, 
teachers, students may at any time to master the experimental information, which may lead to absent, in the wrong place. Now the introduction of SMS technology can be a good solution to this problem. Like an alarm clock to remind, the administrator can through SMS platform preset to send object, sending time, send the contents, prior to the start of each time the experimental classes related to the teachers and students will receive SMS notification, the teaching experiment. And this platform in the future can also be used as an auxiliary tool of educational administration.

\section{Technology realization}

In front of the system development language used ASP.NET/ADO.NET technology, back-end database using Oracle database, logic using more convenient B / S architecture (Browsers/Web servers/Database servers that browser, the server, the students, the backstage database server three layer structure mode). All users web service (teachers, administrators) on any one of the computers on the computer through the browser on the corresponding operation.

User security

First used in the safety of users is user authority management method, all users will be divided into different group, each group of each function module of the information system has the appropriate permissions, and a user can belonging to the one or more groups, has owned the permissions for the group, thus greatly facilitate the management of user. By using MD5 encryption algorithm, when the user login system to user input password to calculate the MD5 value, then go and system stored MD5 values are compared, and the system and "know" what is the password of the user, so in a large extent ensures the safety of users.

Network map guide system

In this system, the MapBasic. ASP.NET Maplnfo. technology and Ajax technology are used to generate a network map which can zoom in and out. Users click on any of the laboratory's name, page refresh will dynamically show the location of the laboratory pictures, easy to use.

The system uses Ajax technology to exchange data with the web server, making the Web page and the small use interrupt interactive process can be re loaded, so as to realize the dynamic update of the network map.

SMS platform based on wireless network through a control terminal and a receiver to achieve the management, transmission and reception. The hardware of the mountain is composed of a server and a wireless Modem, and is connected with the wireless network. This platform uses the current support to send Chinese and English PDU mode to send text messages. First set Modem to PDU encoding mode, and set the encoding conversion mode, if it is Chinese to carry out UNICODE encoding conversion, if the English alphabet 7BIT encoding conversion. And then set the message center address, send a mobile phone address, etc., Modem will be able to send messages out. The working mode of the receiving end is opposite to the control end, and the receiving message content is received by the Modem, and the control end is returned to the control end.

\section{Conclusion}

A new generation of for open experimental teaching of comprehensive resource network support platform to the informationization, intelligent, rich in resources, features a variety of characteristics completely replaced the early artificial management mode and past single function experiment booking management system, embodies the with students as the center of teaching thought, accelerate the pace of information construction of the school, to optimize the allocation of resources of experimental teaching, improve the quality of experimental teaching. Looking to the future, the intercollegiate cooperation and integration of remote collaborative open network experimental platform through hardware, software, and personnel resources share to personnel training of high level and high efficiency and social productivity of the sustained and rapid growth. 


\section{References}

[1] Zhang C M, Shi H S. Study on Information Sharing Platform and Network Open Experiment[J]. Applied Mechanics \& Materials, 2014, 484-485:856-859.

[2] Lian Z Z, Liu X J, Yao-Cheng L I, et al. Probing into collaborative and open experiment teaching model based network platform on computer courses[J]. Journal of Science of Teachers College \& University, 2013.

[3] Wang J J. The Building of College Network Experiment Platform for IPv6 QoS[J]. Applied Mechanics \& Materials, 2013, 443:468-472.

[4] Chen J, Zhou L, Yao G, et al. Study on full-open experiment platform for DFIG wind power generation[J]. Dianli Xitong Baohu Yu Kongzhi/power System Protection \& Control, 2015, 43(10):104-110.

[5] Guolong R, Li Z, Li H, et al. Design of a modular and open innovative experiment and practice platform for electronic information[C]// Consumer Electronics, Communications and Networks (CECNet), 2013 3rd International Conference on. IEEE, 2013:229-233. 